\title{
DOCTRINA \\ Concurrencia del poder central y comunal en un contexto de excepción: ¿Quién es el competente?
}

\author{
Concurrence of central and communal power in a context of exception: \\ $¿$ Who is the competent?
}

\author{
Valeska Opazo de la Fuente \\ Universidad Católica de la Santísima Concepción, Chile
}

\begin{abstract}
RESUMEN Ante la confusión que puede generar un estado de excepción, específicamente en lo que respecta a determinar quién es el titular de las competencias para enfrentarlo, este trabajo busca otorgar una cuota de certeza que permita orientar la concurrencia de autoridades centrales y comunales en dicho escenario. En tal sentido, y a pesar del carácter autónomo de los municipios, postula la preponderancia del jefe de Estado frente al actuar municipal en un contexto de excepción constitucional, como consecuencia del origen gubernativo de dicha declaración. Sin perjuicio de ello, también justifica la intervención del municipio, amparada en sus deberes de colaboración y coordinación con la autoridad central que emanan de la unidad sistémica que caracteriza a la Administración Pública.
\end{abstract}

PALABRAS CLAVE Estados de excepción constitucional, presidente de la República, función de gobierno, municipios, autonomía.

ABSTRACT In the face of confusion that a constitutional state of exception can generate, especially regarding determinate who is the holder of the powers to face it. This work seeks to give a certainty quota, which allows orienting the concurrence of central and communal authorities on said stage. In that sense, despite that the natural autonomy of the local council, it postulates the superiority of the Head of State, in contrast to the municipal act, because of the governmental origin of the declaration of a state of exception. However, this it also justifies the municipal intervention, expressed in the duties of collaboration and coordination with the central authority, like a product of the systemic unity that characterizes the public administration.

KEYWORDS Constitutional state of exception, president of the Republic, government function, municipality, autonomy. 


\section{Introducción}

A propósito de la pandemia que afecta a Chile, se ha observado una permanente tensión entre las autoridades centrales, representadas en el presidente de la República, y las comunales, representadas específicamente por los alcaldes, en torno al ámbito de competencias que le corresponde a cada uno. ${ }^{1}$ Este escenario se ha profundizado como consecuencia de la declaración del estado de excepción constitucional de catástrofe. En este escenario, cabe preguntarse qué responsabilidades deben asumir las autoridades centrales en dicho contexto. Todo esto, tomando en consideración la forma de Estado unitaria y la categoría de acto de gobierno que caracteriza esta declaración. Además de lo anterior, es importante preguntarse cuáles son las competencias de los municipios en el mismo escenario si se atiende al carácter autónomo de estos organismos, reconocido a nivel constitucional, y en el hecho de ser entes integrantes de la Administración Pública.

Las respuestas a estas preguntas resultan relevantes, más en un escenario de excepción constitucional caracterizado por la incertidumbre y la vulnerabilidad que genera en las personas, toda vez que a través de ellas se podrán concretar dos principios estructurales del Estado de derecho: la juridicidad y la finalidad de servicio que le corresponde a la Administración Pública.

Con respecto a la legalidad, la determinación del titular de la competencia permitirá dar certeza y controlar la validez de las actuaciones emanadas de un organismo público. En lo pertinente a la función administrativa, el conocimiento de quién debe (o quiénes) y cómo debe ejercer sus atribuciones disminuye el riesgo de un actuar administrativo inoportuno y/o inadecuado.

En definitiva, el problema que se quiere presentar es el «choque» institucional entre el presidente de la República y los alcaldes, que se genera a propósito de la ocurrencia de un hecho que altera total o parcialmente el normal desarrollo institucional. A fin de dar solución a esta problemática, este artículo, utilizando como hilo conductor un escenario de excepción constitucional, se dividirá en tres partes. En la primera, sobre la base del deber de gobernar y mas allá de la letra del texto constitucional, se justificará la titularidad del presidente de la República para determinar si procede o no la declaración de una situación de excepción. En la segunda, se efectuará una relación entre tal titularidad presidencial y las competencias de los municipios, y, específicamente, se expondrá la razón por la que estos últimos se encuentran excluidos de la declaración de excepción y de sus efectos a pesar del carácter autónomo que les otorga la propia Carta Política. En la última parte, y no obstante lo anterior, se explicarán las modalidades de intervención de las corporaciones municipales en un contexto de anormalidad institucional, las cuales se refieren a los deberes de colaboración y coordinación, y que surgen producto del carácter sistémico de la Administración Pública que incorpora a todos los entes administrativos, tanto centrales como territoriales.

1. Ejemplos concretos de esta tensión fueron consignados por diferentes medios de prensa. Un listado detallado se puede consultar en Szmulewicz Ramírez (2021: 201 y 202). 


\section{Carácter gubernativo de la declaración de un estado de excepción constitucional}

En el ordenamiento jurídico nacional es el presidente de la República el titular de la potestad para declarar un estado de excepción constitucional. Esto es indiscutible por disponerlo así, de manera expresa, el propio texto constitucional en su artículo 32, número $5 .{ }^{2}$ No obstante esta claridad normativa, se considera necesario efectuar una breve explicación teórica que justifique, mas allá del texto político, la titularidad de dicha potestad a fin de comprender por qué y cuál es el rol que le corresponde al jefe de Estado en dicho ámbito, y vincularlo con el papel que, en este mismo contexto, corresponde a los municipios.

De conformidad con los dispuesto en el artículo 3 de la Carta Fundamental, Chile es un Estado unitario. Esto significa, desde el punto de vista de la organización espacial del poder, que en el territorio existe un solo centro de impulsión política y administrativa, un solo centro que gobierna, cuyas decisiones se extienden a todo el territorio y a toda la población (Martínez Sospedra y Uribe Otalora, 2018: 151). No existen en el espacio nacional otras estructuras gubernativas, el Estado constituye un solo centro político de gobierno, que se concreta, según el artículo 24 de la Carta Fundamental, en la figura del presidente de la República. Por lo tanto, desde una perspectiva restringida (Jiménez Larraín y Jiménez Loosli, 2013: 315), ${ }^{3}$ es él y solo él quien gobierna el Estado.

Esta concentración de poder político permite excluir a cualquier otra autoridad en lo que respecta al ejercicio de potestades gubernativas. Exclusión que opera, incluso, en circunstancias extraordinarias o por la necesidad imperiosa de paliar efectos negativos, toda vez que el artículo 7 , inciso segundo, del texto constitucional de 1980, señala expresamente que «ninguna magistratura, ninguna persona ni grupo de personas pueden atribuirse, ni aun a pretexto de circunstancias extraordinarias, otra autoridad o derechos que los que expresamente se les hayan conferido en virtud de la Constitución o las leyes».

Concluir lo contrario, es decir, atribuir funciones de gobierno a autoridades distintas a las señaladas en la Carta Fundamental, cualquiera sea la justificación, simplemente significaría infringir el principio de juridicidad y el Estado de derecho, acarreando la nulidad de la decisión y las posibles consecuencias reparatorias.

Que la máxima autoridad estatal gobierne significa que puede:

2. Se pueden sumar otras disposiciones constitucionales que nos conducen a la misma conclusión, por ejemplo, el inciso segundo del artículo primero, al señalar que es deber del Estado dar protección a la población y a la familia en relación con el artículo 24, que consagra al presidente de la República como jefe del Estado.

3. El gobierno, en sentido restringido, se refiere a las autoridades superiores del Estado encargadas de su administración y de la aplicación de la ley, en contraposición al sentido amplio, que comprende también a los organismos responsables de la creación de ley. 
Mandar, dirigir el Estado en su conjunto con decisiones políticas en todos los asuntos que no sean, según la Constitución y las leyes, competencia de otras autoridades públicas y con respecto a las cuales sea indispensable obrar con discrecionalidad, prudencia, liderazgo y creatividad para el bien común, sin estar el gobernante subordinado a normas previas exhaustivas, pero sin tampoco violar el orden jurídico vigente (Cea Egaña, 1997).

De la definición expuesta, se deduce que gobernar significa: i) tomar decisiones dentro de un abanico de posibilidades jurídicamente permitidas; y ii) que estas medidas se encuentren directamente relacionadas con algún aspecto esencial del Estado, ya sea en lo que respecta a sus elementos, finalidad o funcionamiento, por ejemplo, en lo relativo al orden público sanitario, económico o al ejercicio de la soberanía.

Por tanto, dos notas características le otorgan fisonomía al acto de gobernar: la primera es el ámbito de discreción que antecede la decisión gubernativa (García de Enterría y Fernández, 2017: 505). ${ }^{4}$ Es decir, el jefe de Estado, previo al acto decisorio, se enfrenta a una amplitud de posibilidades, todas válidas, que pueden ser objeto de la decisión, razón por la cual deberá efectuar un ejercicio intelectual que le permita evaluar las distintas situaciones, cursos de acción, elección de alternativas, oportunidad, modalidades de ejecución, etcétera (Cea Egaña, 1991: 14), a fin de decidir cuál es la solución idónea a una necesidad o interés público determinado. Desde esta perspectiva, el acto de gobierno se encuentra vinculado a la razonabilidad y a la prudencia de la máxima autoridad, y desconectado de condicionamientos previos de carácter legislativos (Fayt, 1998: 87; Caldera Delgado, 1989: 423 y 424). ${ }^{5}$ El segundo rasgo característico de la función de gobernar es su contenido. La decisión que se adopta, como resultado de este proceso intelectual, consiste en directrices o grandes orientaciones que deben regir a la sociedad y a los órganos públicos para alcanzar determinadas metas u objetivos esenciales, «implica la alta dirección de los negocios públicos de la nación [...] la ejecución de actos que miran a problemas que son fundamentales para el Estado [...] corresponde a las más altas autoridades» (Celis Danzinger, 2010: 5).

Si este breve análisis se aplica a la declaración de un estado de excepción constitucional, es posible concluir que esta decisión es un acto de gobierno y, por tanto, de competencia de la única autoridad facultada para gobernar el Estado, quien es el presidente de la República (Sentencia de la Corte Suprema de Justicia, rol 4029-13, 2013:

4. Lo que caracteriza a un acto de gobierno es su discrecionalidad, es decir, en palabras de García de Enterría, «la libertad de elección entre alternativas igualmente justas, o, si se prefiere, entre indiferentes jurídicos, porque la decisión se fundamenta normalmente en criterios extrajurídicos (de oportunidad, económicos, etcétera)». Este destacado y los siguientes son nuestros. Este carácter esencial de discrecionalidad es lo que permite argumentar que estos actos no son controlables por el juez: «el juez no puede fiscalizar la entraña de la decisión discrecional, puesto que, sea esta del sentido que sea [...] es necesariamente justa».

5. Sin embargo, siguiendo a Caldera Delgado, se debe hacer presente que el ejercicio de cualquier potestad debe sustentarse siempre en el ordenamiento constitucional, es decir, nunca debe desbordar o sobrepasar el texto constitucional, en razón de la preeminencia de este último. 
considerando duodécimo). ${ }^{6}$ Primero, se está en presencia de un hecho que afecta o pudiese afectar gravemente el normal funcionamiento de las instituciones del Estado (Zúñiga Urbina, 2014: 519)7 conforme al artículo 39 de la Carta Fundamental. Segundo, la respuesta a esta situación dependerá del ámbito subjetivo de discrecionalidad de la máxima autoridad estatal, lo cual, como se señaló, implica la posibilidad de adoptar decisiones cuyo contenido no se encuentre reglado, con la finalidad de solucionar conflictos relevantes para la institución estatal.

Por tanto, en términos prácticos, es el presidente de la República, por ser la única autoridad que gobierna el Estado, quien decide, racional y prudentemente, ante alguna situación que amenace o genere grave riesgo para las instituciones estatales y sociales, declarar un estado de asamblea, de sitio, de catástrofe, etcétera, a fin de evitar, mitigar o terminar con sus efectos. Si frente a la misma circunstancia fáctica la autoridad tomara otra decisión que, a su juicio y dentro del orden jurídico-constitucional, fuera la prudente y proporcional a la situación acaecida, por ejemplo, no declarar un estado de excepción y enfrentar el hecho con los medios jurídicos ordinariamente dispuestos, también sería un acto de gobierno.

A las alternativas anteriores se puede sumar una tercera. En efecto, en el evento que ocurra un sismo o una catástrofe que provoque daños de consideración en las personas o en los bienes, la máxima autoridad podría hacer uso de lo dispuesto en la Ley $\mathbf{1 6 . 2 8 2}$ por estimar que, a su juicio, esta es la solución idónea para la gravedad del hecho acaecido. Esta normativa le permite al jefe de Estado dictar un decreto supremo que contenga las zonas afectadas y adoptar medidas extraordinarias para enfrentar tal situación. Por ejemplo, puede dictar normas de excepción al Estatuto Administrativo y a las leyes orgánicas de los servicios públicos. Todo esto según el artículo 3 de la Ley 16.282 de $1965 .{ }^{8}$ Incluso, puede existir una cuarta posibilidad, que es adoptar ambos estatutos de manera simultánea, es decir, estados de excepción constitucional y la Ley 16.282.

6. La Corte Suprema, tomando como argumento que la declaración de un estado de excepción constitucional corresponde a un acto político propio del jefe de Estado, ha negado el control judicial sobre este tipo de decisiones, señalando en el fallo referido que «la regulación de los estados de excepción implica la concurrencia de exigencias cuya verificación es de resorte exclusivo del gobierno. En efecto, la Constitución Política manda sin equívocos que se excluye rotundamente del control judicial el acto administrativo dictado en ejercicio de la potestad de gobierno y discrecional relativa a la declaración de estados de excepción constitucionales, la cual no es susceptible de ser fiscalizada por los Tribunales. Ello tiene como fundamento no solo la disposición expresa constitucional, sino que también la circunstancia de que el control jurisdiccional tiene como límite divisorio los actos que son propios de la actividad política, en este caso de la autoridad máxima de gobierno, de suerte que los órganos jurisdiccionales no se encuentran autorizados para revisar decisiones de esta índole». Una importante doctrina coincide con esta posición. Para más información, véase Zúñiga Urbina (2014: 519) comentando la sentencia citada, y Silva Irarrázaval (2018: 90 y 91).

7. Zúñiga Urbina expresa que «el fin común de los estados de excepción es la defensa extraordinaria del Estado nación frente a una situación de anormalidad que afecte gravemente el normal desenvolvimiento de las instituciones del Estado».

8. Pueden consultarse otras medidas excepcionales en el artículo referido. 
La importancia de todo lo expuesto es evidente. Frente a un escenario incierto y amenazante, como lo es el provocado por terremotos, pandemias o agresiones externas, el ordenamiento jurídico se encarga de otorgar una cuota de certeza, identificando a la autoridad responsable de enfrentar tal situación y entregándole las competencias necesarias para ello.

Esta certeza jurídica facilita la rapidez y la eficacia en la toma de decisiones, lo cual, a su vez, permitiría cumplir con la finalidad perseguida por esta regulación de excepción, que es el pronto restablecimiento de la normalidad según lo dispuesto por el artículo 44 de la Carta Fundamental. Además, hace posible un principio rector del Estado de derecho, que en un contexto de excepción cobra aun mayor relevancia: el control. En efecto, la existencia de instancias que permitan verificar el ajuste de las decisiones político/administrativas con la realidad jurídica resulta imprescindible debido a:

- La concentración de poder que se genera en el órgano ejecutivo, acentuado por el presidencialismo que rige al país.

- Las medidas que se pueden adoptar para enfrentar la situación de excepción, entre las que destaca la afectación de derechos y libertades esenciales, como lo es la propiedad, el libre tránsito y el derecho de reunión.

- El ámbito de discrecionalidad que caracteriza la adopción de estas medidas, lo cual podría utilizarse como excusa para un actuar público excesivo, arbitrario o desviado, como ocurría bajo la Constitución Política de 1925 (Pfeffer, 2002).

En tal contexto, el propio ordenamiento jurídico establece condiciones al actuar del jefe de Estado, por ejemplo, en lo que respecta a la intervención del Congreso Nacional y a la duración de la situación de excepción (Constitución Política de la República de Chile, 1980: artículos 40 a 42; Ley 18.415, 1985: artículo 8);9 y resguarda los derechos fundamentales frente a medidas excesivas o desviadas según el artículo 45 de la Carta Fundamental. ${ }^{10}$

9. La Ley 18.415 se denomina «Orgánica Constitucional de los Estados de Excepción».

10. No se debe confundir la distensión del control judicial con respecto al acto político que califica los fundamentos y las circunstancias de hecho invocadas por la autoridad para declarar un estado de excepción constitucional (para más información, véase la cita 6), de aquellas medidas administrativas adoptadas en dicho contexto y que repercuten directamente en la esfera jurídica de las personas, especialmente aquellas que suspenden o restringen derechos fundamentales. Estas sí deben ser controladas por los Tribunales de Justicia a fin de verificar su temporalidad, provisionalidad, racionalidad, proporcionalidad y justiciabilidad (Zúñiga Urbina, 2014: 518). Como ejemplo puede verse el fallo de la Corte Suprema (rol 150.549-20, 2021: considerandos undécimo, decimosegundo y decimotercero) que acogió un recurso de protección interpuesto en contra de la seremi de Salud de la Región del Biobío. La autoridad sanitaria, en el contexto de la situación de excepción que vive el país, a propósito de la pandemia, prohibió a un establecimiento comercial la venta de artículos de librería por considerar que no eran esenciales. La Corte sostuvo la arbitrariedad de dicha medida, por cuanto la misma autoridad permitía la venta de los mismos artículos a otros negocios sin justificar la razón de esta decisión. En definitiva, se sostuvo que la actuación administrativa afectaba el derecho de igualdad. 
Por tanto, si tomamos en cuenta que nos encontrarnos insertos en una forma de estado unitaria, que se caracteriza por la existencia de un solo centro con potestades gubernativas y que, por lo mismo, excluye a cualquier otra autoridad del ejercicio del gobierno (Zúñiga Urbina, 2014: 518); ${ }^{11}$ y que este significa adoptar decisiones de carácter discrecional y relacionadas con algún aspecto estructural del Estado, la potestad de declarar un estado de excepción de constitucional recae, exclusivamente, en el presidente de la República. Las mismas razones justifican que, en tal contexto, también sea el jefe de Estado quien pueda adoptar medidas que signifiquen afectar o restringir derechos fundamentales (Dictamen de la Contraloría General de la República 6.785, 2020).

Esta certeza jurídica, sobre la titularidad de las potestades en un escenario de excepción, evita la dispersión o los conflictos de competencias, facilita la unidad y la rapidez en la gestión, y permite controlar el ejercicio de facultades. Todo lo cual garantiza que el poder continúe desarrollándose en un ambiente de razonabilidad, cordura y al servicio de la persona humana como fin del Estado, es decir, permite el funcionamiento democrático de las instituciones a pesar de la situación de anormalidad.

\section{La función de gobierno y la autonomía de los municipios a propósito de una situación de excepción constitucional}

Explicado que la declaración de un estado de excepción constitucional corresponde a un acto de gobierno cuyo titular es el presidente de la República, es oportuno preguntarse cuál es el rol que le corresponde a los municipios en dicho contexto. Esta pregunta se fundamenta en el carácter autónomo de los entes edilicios con respecto al poder central, lo cual podría dar entender que, no obstante la explicación previa en torno a la función gubernativa, las municipalidades estarían facultadas para adoptar medidas en un contexto de anormalidad institucional. Para responder la pregunta, se analizará la autonomía municipal con respecto a sus funciones propias, compartidas y en relación con la función de gobierno.

\section{Actuar municipal autónomo en sus funciones propias y compartidas}

Primero, se debe hacer presente que, así como a la máxima autoridad le corresponde gobernar, también es la responsable de administrar el Estado según el artículo 24 de la Carta Fundamental y el artículo 1 de la Ley 18.575.

Esta última función significa que el presidente de la República debe disponer de los recursos existentes para satisfacer dos tipos de necesidades:

- Las que afectan a las personas de manera habitual o cotidiana, y que, por tal circunstancia, requieren ser cubiertas de manera continua y permanente. Por

11. Es indiscutible que la decisión acerca del estado de excepción es política: intervienen los poderes constituidos en su declaración, siendo el impulso fundamental del presidente de la República. 
ejemplo, necesidades educacionales o de salud, reparación de calles, etcétera, según lo señala el artículo 3 de la Ley 18.575.

- Aquellas relacionadas con la adopción de un acto de gobierno. Por ejemplo, la ocurrencia de un terremoto o una pandemia genera en la población la necesidad de protección y, para satisfacerla, el presidente de la República puede decretar un estado de excepción constitucional.

Hecho esto, la función administrativa es la encargada de concretar tal decisión mediante acciones tangibles, es decir, los organismos administrativos deben "poner en obra, ejecutar las políticas, los planes y programas» (Caldera Delgado, 1991: 205 y 206) ${ }^{12}$ encuadrados dentro del concepto de acto de gobierno y emanados del poder central.

Ambos tipos de necesidades, las cotidianas y aquellas que justifican una decisión política, se caracterizan por ser complejas y múltiples, razón por la cual el legislador ha establecido que, en la labor de administrar y de gobernar, la máxima autoridad cuenta con la colaboración de los órganos que integran la Administración Pública. Todo esto según el artículo 1 de la Ley 18.575 de 1986. Uno de estos entes son las Municipalidades. Como se sabe, estas son corporaciones autónomas de derecho público, con personalidad jurídica y patrimonio propio, cuyo deber es administrar una comuna o agrupación de comunas según lo dispone el artículo 1 de la Ley Orgánica Constitucional de Municipalidades y el artículo 118 de la Carta Fundamental.

La forma organizativa, a través de la cual las corporaciones municipales satisfacen las necesidades permanentes y propias de la respectiva comunidad local, no es la descentralización ni la centralización, sino la llamada, a nivel doctrinario, acentralización (Pantoja Bauzá, 2010: 22). Esta expresión refleja que los municipios concretan su objeto legal de manera autónoma, es decir, administran los intereses comunales de forma independiente, lo cual se expresa en el aspecto funcional de los municipios.

En efecto, se sabe que las corporaciones edilicias son titulares exclusivas de ciertas tareas en el ámbito comunal, según lo dispone el artículo 3 de la Ley Orgánica Constitucional de Municipalidades. ${ }^{13}$ Esto significa que pueden concretar sus funciones sin necesidad de vincularse con otro ente, por disponerlo así el propio texto legal (Sentencia del Tribunal Constitucional, rol 1669-10, 2012: considerando vigésimo). Además, la misma ley les permite desarrollar otras labores que se encuentran relacionadas a bienes habituales y de importancia para todo el grupo humano que conforma el Estado, por ejemplo, educación, cultura, salud pública, etcétera. Por la relevancia y generalidad de estas necesidades, existen otros organismos administrativos que también intervienen en su satisfacción, como Ministerios, Secretarías Regionales, etcétera, cuyo accionar se

12. Sin la función administrativa, Caldera Delgado expresa que «las metas políticas del gobierno permanecerían, indefinidamente, como meros programas o proyectos incumplidos».

13. Como ejemplos de estas funciones se pueden señalar: elaborar, aprobar y modificar el plan comunal de desarrollo, la promoción del desarrollo comunitario, aplicar las disposiciones sobre transporte y tránsito público, sobre construcción y urbanización; y el aseo y ornato de la comuna. 
extiende a todo el territorio nacional. Por lo mismo, en estas materias enumeradas en el artículo 4 de la ley orgánica señalada, los municipios pueden concretar sus labores de manera directa o con estos otros órganos de la Administración Pública.

En relación con lo anterior, y no obstante la obviedad, se hace presente que en ningún caso los entes municipales pueden abordar materias que sean de competencia de estos otros organismos, de conformidad con el principio de legalidad y según lo dispuesto en el artículo 2 de la Ley 18.575. Solo pueden concretar tareas relacionadas, es decir, pueden poner en práctica alguna iniciativa que tenga conexión o correspondencia con alguno de los ámbitos enumerados en el artículo 4, con la finalidad de potenciar dicho sector y/o mejorar la calidad y oportunidad en la satisfacción de la necesidad pública en específico, pero en ningún caso pueden intervenir en el objeto legal de otros organismos administrativos vinculados a la misma área.

Por tanto, hasta el momento, y con la finalidad de ir delimitando el rol que corresponde a estas corporaciones en un contexto de excepción, se puede señalar que los municipios gozan de autonomía para actuar: i) en materias que el legislador les ha entregado de manera exclusiva; y ii) en otras en las que su accionar puede ser directo o con otros órganos de la Administración.

Como es el legislador orgánico quien, directamente, ha atribuido a los municipios las tareas a desplegarse y la forma en la que se deben concretar (Sentencia del Tribunal Constitucional, rol 80-89, 1989: considerando quinto), el poder central no interviene en la ejecución de estas funciones. Por lo mismo:

No hay normas que permitan vetar o suspender decisiones que adopten sus autoridades por parte de las autoridades administrativas nacionales. En este sentido, [los municipios] deciden de manera definitiva, sin que sus opciones puedan ser sustituidas o mediatizadas jurídicamente por actos del poder central (Sentencia del Tribunal Constitucional, rol 1669-10, 2012: considerando decimoctavo).

En consecuencia, al gobierno le está vedado ejercer una más de relación de tutela o supervigilancia y menos de jerarquía con respecto al actuar de las autoridades municipales (Pantoja Bauzá, 2010: 22). El presidente de la República no puede influir ni intervenir en el comportamiento de alcaldes y concejales.

Esta ausencia de superioridad jurídica por parte del nivel central se justifica, a nivel político, en el hecho de que ambas autoridades, centrales y comunales, son elegidas democráticamente por la ciudadanía. Esta idéntica fuente de elección, con los reparos respectivos en lo que respecta al universo de votantes, genera una relación horizontal entre municipio y presidente de la República, que le impide a este último ejercer un poder jerárquico o de tutela con respecto a las autoridades territoriales. En el evento que así fuere, se estaría vulnerando la voluntad comunal. A nivel jurídico, la justificación se encuentra, como lo dijo el Tribunal Constitucional, en la atribución legal de funciones.

Producto de este ejercicio autónomo, generado por la elección democrática de sus autoridades y por la asignación normativa de las funciones y atribuciones municipales, lo cual significa inhibir al poder central en el desarrollo de acciones jerárquicas o 
de tutela, se puede concluir que los municipios son «titulares de sus propios poderes» (Zúñiga Urbina, 2007: 229) o, como lo ha dicho el Tribunal Constitucional:

No son solo órganos dotados de poder administrativo, sino también dotados de un cierto poder político [...] tienen amplias potestades configurativas, producto de su autonomía. Ello se expresa [...] en que tienen instrumentos de configuración social, que les permiten no solo ejecutar disposiciones, sino también crearlas y con ello contribuir a «crear las condiciones sociales» que permitan la «mayor realización material y espiritual posible» de las personas (Sentencia del Tribunal Constitucional, rol 166910, 2012: considerando 21).

Por tanto, con respecto a estas corporaciones existiría una distribución del poder circunscrito al espacio geográfico de la respectiva comuna. Esta afirmación podría reflejar, como primera impresión, que el actuar municipal se encuentra revestido de una extensa autonomía que les permitiría adoptar decisiones de carácter político, al igual que el jefe de Estado, a fin de administrar los intereses y necesidades comunales, por ejemplo, en un contexto de excepción constitucional. Sin embargo, un análisis detallado nos obliga a una conclusión distinta.

\section{Actuar municipal autónomo y su exclusión de la función de gobierno}

A propósito de la pandemia que afecta al país, varios municipios, invocando sus atribuciones legales, especialmente la contenida en el artículo 4, letra i, de su ley orgánica, que los habilita para desarrollar acciones consistentes en prevenir riesgos y prestar auxilio en situaciones de emergencia o catástrofe; como también disposiciones contenidas en el párrafo tercero del Código Sanitario, que se refieren a las atribuciones y obligaciones sanitarias de las municipalidades, adoptaron medidas que suspendieron o restringieron derechos fundamentales, como declaraciones de emergencia, cuarentenas comunales y restricciones al tránsito local, entre otras, según consta en Dictamen 6787 de 2020 de la Contraloría General de la República. Estas medidas, que reflejan una evidente tensión entre organismos territoriales autónomos y el poder central (Soto Delgado, 2021: 69 y 70), fueron declaradas contrarias a derecho por parte del organismo contralor, indicando, expresamente, que no es de competencia de las municipalidades decretar medidas como las aludidas y, acto seguido, se les ordenó la revisión de dichas acciones a fin de ajustarlas al ordenamiento jurídico. En el mismo dictamen, la Contraloría precisó al organismo competente para afectar derechos fundamentales en un contexto de excepción, cual es el presidente de la República.

La declaración del organismo contralor, consistente en sustraer del ámbito municipal la actividad de policía sanitaria derivada de una situación de anormalidad institucional, y radicarla en el poder central (Soto Delgado, 2021: 73), se basa, a nuestro entender, en la incompetencia de los organismos comunales para adoptar decisiones de gobierno, a pesar de su autonomía, en virtud de lo dispuesto en el propio texto constitucional y por el origen democrático de las autoridades municipales. 
En efecto, a propósito de lo señalado en la Carta Política, se reitera lo dicho con respecto al carácter unitario del Estado contemplado en el artículo 3 del texto constitucional, es decir, que en Chile existe un solo centro de impulsión gubernativa, un solo centro titular de la potestad habilitante para tomar decisiones discrecionales capaces de satisfacer necesidades trascendentes para la comunidad, independiente de que estas tengan un carácter nacional o subnacional, por ejemplo, dar protección a la población producto de una pandemia o generar políticas habitacionales. Esta concentración del poder político, derivada del inciso primero de la norma indicada, se refuerza con lo señalado en su inciso segundo, en el sentido de que la descentralización y la desconcentración a la que alude el texto político se extiende, exclusivamente, a la función administrativa. Lo anterior significa que, si bien el constituyente permite modalidades de acción que signifiquen transferencia de poder, la doctrina ha entendido que estas deben limitarse al actuar administrativo y no pueden extenderse al ámbito político (Bermúdez, 2014: 398 y 399). En consecuencia, no es posible postular que el alcalde sea titular de potestades gubernativas al igual que el jefe de Estado, porque ello significaría aceptar la existencia jurídica de frenos y contrapesos políticos-territoriales hacia la autoridad central, lo cual no es permitido por la norma constitucional.

Complementa el argumento anterior, en relación con la imposibilidad de que las corporaciones edilicias ejecuten actos gubernativos, no obstante su autonomía, la elección democrática de las autoridades comunales. Sabemos que la Carta Fundamental, para efectos de concretar la labor de gobierno, señala que el territorio del Estado se divide en regiones y estas en provincias (Constitución Política de la República, artículo 110), regiones y provincias cuya máxima autoridad es designada y removida por el propio jefe de Estado: los delegados presidenciales regionales y provinciales. Estos agentes públicos representan al poder central y actúan siguiendo sus órdenes y directrices. En consecuencia, a través de ellos el presidente de la República prolonga su poder de gobierno y de administración en cada una de las regiones y provincias del territorio. Por tanto, no es posible que esta extensión del ejecutivo ocurra en el ámbito comunal, toda vez que en este espacio la autoridad superior es elegida democráticamente por la propia localidad y no es designada por el poder central.

Al no existir designación, sino que elección, el jefe de Estado no puede dictar pautas o reglas que guíen el actuar municipal porque, como se ha señalado, han sido los habitantes de la comuna quienes, directamente, han elegido a la autoridad responsable de administrar sus intereses. Dicho en otros términos, a diferencia de lo que ocurre con las autoridades designadas, el presidente de la República se encuentra impedido de dar órdenes o asignar tareas al alcalde. Por ende, no puede gobernar a través de él. ${ }^{14}$ Esto explica que en un estado de excepción constitucional, por ejemplo, el de ca-

14. Por tal razón es que la acusación constitucional solo puede dirigirse con respecto a autoridades que ejerzan la función de gobierno a nivel nacional, regional o provincial. La Cámara de Diputados no puede fiscalizar actos que provengan de autoridades distintas a estas, por ejemplo, aquellos emanados de los municipios (Soto Kloss, 2010: 529 y 530). 
tástrofe, la autoridad militar pueda adoptar medidas que impliquen restricciones a los derechos fundamentales, como son aquellas contempladas en el artículo 43 de la Carta Política, toda vez que, de conformidad al artículo 6 de la Ley 18.415, el presidente de la República puede delegar sus facultades en los jefes de la defensa nacional que «él designe», siendo una de las atribuciones del jefe de Estado, precisamente, afectar garantías constitucionales.

En consecuencia, la elección democrática de alcaldes y concejales impide ampliar la función gubernativa al ámbito comunal y la circunscribe a los espacios regionales y provinciales, limitando el objeto legal de los municipios solo a la administración de la comuna (Huidobro, 2011: 5; Fernández Richard, 2013: 151 y 152).

Los argumentos previos constituyen, en definitiva, un reconocimiento al principio de juridicidad en un contexto de excepción, en el sentido de que, si bien el escenario fáctico exige un actuar pronto y eficaz a fin de devolver la normalidad institucional, ello no significa suspender el vigor del ordenamiento jurídico, mas aun si existe la posibilidad de suspender o restringir derechos fundamentales, ya que este continúa aplicándose tanto en lo pertinente a aquellas reglas previstas para situaciones de anormalidad institucional, principalmente de carácter constitucional, como también en todo aquello que sea necesario aplicar, por ejemplo, las reglas que regulan la organización y las atribuciones de los distintos organismos estatales (Bassa, 2020: 15). Dicho de manera simple, «el gobierno de la norma jurídica, aun en la excepción» (Tejos Canales, 2006: 134).

Por lo demás, se reitera el deber que el inciso segundo del artículo 7 del texto político le impone a la autoridad, consistente en ajustar su acción a las facultades reconocidas por la ley y la Constitución aun en casos de circunstancias extraordinarias. Esta norma fulmina cualquier posibilidad de actuación pública que carezca de una expresa habilitación legal previa, independiente del contexto en el que se desarrolle (Valdivia, 2020: 33). La Carta Política es clara y suficiente cuando niega la imprevisibilidad de una situación de anormalidad, la capacidad de otorgar potestades que habiliten la libre determinación de autoridades administrativas (Pantoja Bauzá, 2000: 160). Por ello es que en un escenario de normalidad o anormalidad todos los órganos estatales, por ejemplo, municipalidades o fuerzas armadas, siempre deben ajustarse al derecho, mas aun si existe la posibilidad de afectar derechos fundamentales de suma relevancia, como lo es la libertad personal y sus repercusiones en ámbitos como la libertad de reunión o el dominio sobre el cuerpo (Valdivia, 2020: 36). Complementa lo anterior el hecho de que el propio texto político, al regular las situaciones de excepción y mandatar al legislador para que dicte la legislación respectiva, en el artículo 44 señala expresamente que esta «no podrá afectar las competencias y el funcionamiento de los órganos constitucionales ni los derechos e inmunidades de sus respectivos titulares».

Los argumentos previos permiten comprender la razón por la que los municipios se encuentran impedidos de adoptar decisiones de gobierno en el territorio comunal, como lo son aquellas tomadas en un contexto de excepción y que afectan derechos 
fundamentales. ${ }^{15}$ Estas son medidas que caen dentro de un abanico de discrecionalidad y se refieren a aspectos trascendentales para el funcionamiento estatal: qué mas trascendental que limitar o restringir garantías constitucionales por los organismos del Estado, producto de la situación de emergencia acaecida, cuando el deber de estos es, precisamente, todo lo contrario: respetar y promover los derechos esenciales que emanan de la naturaleza humana, según el artículo 5 de la Carta Fundamental.

Estas medidas, al reunir los elementos para configurarlas como actos de gobierno, discreción e importancia estatal, son resorte del presidente de la República: en un Estado unitario solo a él le corresponde tal función y la proyecta en el territorio a través de las autoridades por él designadas y que lo representan. Este orden jurídico ni siquiera admite excepciones a propósito de una situación de emergencia, y no es posible asumir la posibilidad de un poder gubernativo de carácter implícito, justificado en la urgencia, necesidad o circunstancias extraordinarias (Soto, 2010: 1.379), ya que ello significaría vulnerar el principio de juridicidad contemplado en el artículo 7 de la Carta Fundamental.

En razón de lo expuesto, el cuestionamiento que surge es cómo justificar la intervención del municipio en un contexto de anormalidad institucional producido por una declaración de excepción o por aplicación de la Ley 16.282, toda vez que tal escenario, como se ha señalado, responde a la función gubernativa, actividad de la cual los entes municipales se encuentran excluidos.

\section{Justificación del rol municipal en la función de gobierno a propósito de un estado de excepción constitucional}

A fin de definir cuál es el papel de las corporaciones edilicias en un ámbito de excepción o de sismo o catástrofe, lo primero que se debe señalar es que, de conformidad con los artículos 28 y 29 de la Ley 18.575, los servicios públicos se relacionan con el jefe de Estado a través de los vínculos de jerarquía y supervigilancia. Esto significa que, con respecto a todos ellos, el presidente de la República ejerce un control más o menos intenso, cuya finalidad es garantizar que el actuar de estos organismos se ajuste a las decisiones de gobierno y administrativas que adopta la máxima autoridad estatal. Por tanto, es clara la función que le corresponde a estos entes públicos/administrativos en el contexto de la labor del jefe de Estado: a través de ellos la autoridad central prolonga su poder por medio de los vínculos de jerarquía (servicios centralizados) y de tutela (descentralizados).

Esta forma de relación que se genera entre el poder central y los servicios públicos, y que permite concretizar los actos de gobierno, no procede tratándose de los municipios (Sentencia del Tribunal Constitucional, rol 1669-2010, 2012: considerando

15. Una opinión distinta puede consultarse en Soto Delgado (2021: 76), que justifica las medidas de policía sanitaria municipal en un contexto de excepción sobre la base de una norma legal genérica. El mismo trabajo contiene una interesante revisión histórica sobre tales acciones. 
decimoctavo) ${ }^{16}$ Estos, según se ha señalado, son titulares de sus propias funciones y no dependen ni se relacionan con el poder central a través de ningún tipo de vínculo (Pantoja Bauzá, 2010: 22), por tanto, se podría concluir que se encuentran aislados de las decisiones gubernativas. Sin embargo, que los entes municipales gocen de autonomía para efectos administrativos no significa que el ejercicio de sus atribuciones se concrete de manera paralela o separada del poder central. Por el contrario, sus funciones se encuentran integradas, al igual que cualquier otro organismo estatal, en el ordenamiento jurídico que los rige, compuesto por preceptos constitucionales, legales, reglamentarios, etcétera (Dictamen de la Contraloría General de la República 16.818, 1993).

Dentro de estas disposiciones se encuentra lo señalado en el artículo 1 y 5 de la Ley 18.575. El primero impone a todos los organismos administrativos, sean autónomos, descentralizados o centralizados, colaborar con el presidente de la República a fin de que pueda concretar sus funciones de gobierno y de administración. El segundo les exige cumplir sus cometidos coordinadamente y propender a la unidad de acción.

Por tanto, el actuar autónomo de las municipalidades no es ajeno a las funciones de otros servicios públicos y del actuar del jefe de Estado. Por el contrario, se entiende formar parte de estos de conformidad a las modalidades de actuación que les impone el derecho, cuales son el deber colaborativo y de coordinación. Por lo demás, la propia Contraloría General de la República, cuando le niega a las municipalidades la posibilidad de inmiscuirse en decisiones de gobierno emanadas de una declaración de excepción constitucional, añadió que ello es:

Sin perjuicio de la colaboración que corresponda prestar a los municipios en el respectivo ámbito local y de la coordinación que debe existir entre los distintos órganos de la Administración del Estado, de acuerdo con los artículos 3 y 5 de la citada Ley 18.575 (Dictamen 6783, 2020).

\section{Deber colaborativo de los municipios en la función de gobierno}

Junto a las funciones privativas o compartidas de los entes municipales, existen una multiplicidad de otras tareas que no les corresponden a los municipios y que se encuentran vinculadas con necesidades de la población, razón por la cual requieren ser satisfechas de manera permanente y continua. Para cubrir este universo de otras materias no municipales, por ejemplo, aquellas relativas a necesidades de carácter nacional que trascienden los límites comunales, como educación o una pandemia global, se requiere la intervención del jefe de Estado a través de sus funciones de gobierno y administra-

16. La circunstancia de que los municipios se encuentren exentos de esta relación de dependencia o supervigilancia con respecto al poder central ha sido señalada por el Tribunal Constitucional en la sentencia referida al indicar que estos: «son órganos cuyas funciones y atribuciones se ubican en un escalón superior de autonomía con respecto al poder central en relación con los órganos descentralizados [...] estos entes no están sujetos al poder jerárquico del presidente de la República. Pero, mas aun, los órganos autónomos no están sujetos ni siquiera al control indirecto o de tutela propio de los organismos descentralizados». 
ción, las cuales las concreta con la colaboración de los servicios públicos. Deber colaborativo que, como se señaló, se fundamenta en la jerarquía o tutela.

Si esto se traslada al ámbito municipal, se podría concluir que, en razón de su carácter autónomo, estas corporaciones se encuentran excluidas de la obligación de colaborar en estas otras tareas, debiendo concentrarse, únicamente, en sus funciones privativas y compartidas. Sin embargo, como se ha adelantado, esta afirmación es errada. El error consiste en desconocer el carácter integrante de las corporaciones edilicias en la Administración Pública. Esta integración, si bien las obliga a actuar de conformidad a sus propias competencias, además les impone el deber de conjugarse con una pluralidad de otros servicios administrativos (Cea Egaña, 2012: 409) y con el presidente de la República, toda vez que todos forman parte de un único sistema de administración ${ }^{17} \mathrm{y}$ comparten un objetivo común, cual es la obligación general de servicialidad del Estado contemplada en el artículo 1 de la Constitución Política y en el artículo 3 de la Ley 18.575.

Esta obligación constituye un deber jurídico que se le impone a todos los organismos estatales (Soto, 2010: 107), incluidos los autónomos. En consecuencia, significa que las corporaciones municipales, como expresión estatal, tienen la obligación constitucional de servicio a la persona, de dar protección a la población y a la familia, y de respetar y promover los derechos esenciales que emanan de la personalidad.

Por tanto, como el ámbito de las llamadas funciones privativas es escaso y en lo que respecta a sus atribuciones compartidas no pueden invadir las competencias de otros servicios públicos, la forma en la que deben cumplir este principio de servicialidad, además de concretar sus labores propias, es trabajando con otros organismos administrativos y con el presidente de la República para la realización, oportuna y eficaz, de este deber constitucional. Es decir, colaborando en la satisfacción de todas aquellas otras necesidades que no se encuadran dentro de su objeto específico y de sus funciones, ${ }^{18}$

17. Para referirse a este sistema, algunos autores han utilizado la expresión «principio de colegialidad», que hace referencia a una asociación que se organiza como un colegio, corporación o conjunto de personas que trabajan como un todo y que es importante para el aparato administrativo porque le permite satisfacer, en lo posible, todos los requerimientos que el interés general comprende (Boloña, 2010: 63).

18. En esta labor de cooperación se observa con nitidez la fragilidad que presenta la autonomía municipal frente a la potestad del poder central. En efecto, como la finalidad de este deber es concretar o implementar una política o programa nacional, los municipios se ven, en la práctica, subordinados a esta y transformados en simples ejecutores de alguna solución, la cual, muchas veces, es uniforme y no considera la realidad específica y distintas de cada comuna (geográfica, poblacional, cultural, etcétera). Esta observación es importante, porque la municipalidad es la cara visible y mas próxima del Estado para la ciudadanía, lo cual significa que las personas, para enfrentar sus problemas inmediatos y habituales, como el transporte, recreación, salubridad, etcétera, recurren y generan relaciones jurídicas con las corporaciones municipales, no con el servicio público que generó la medida a aplicarse en el territorio comunal (Fernández Richard, 2013: 151), por tanto, una solución que emane del poder central presenta el riesgo de ser inadecuada e inoportuna. La importancia de las administraciones locales es, precisamente, su cercanía con las personas que conforman la comunidad política. Esto facilita una gestión efectiva toda vez que permite observar con mayor claridad las discrepancias existentes entre la norma abstracta y la necesidad local (Chible Villadangos, 2020: 42). 
por ejemplo, las que justifican la declaración de un estado de excepción, pero que son necesarias para el bienestar colectivo. Se hace presente que, desde esta perspectiva, es incuestionable que la administración central goza de preponderancia frente a la comunal, toda vez que es la responsable de un mayor número de necesidades públicas: salud, medioambiente, orden interno, educación, etcétera (Camacho, 2010: 278).

Este deber de actuación integrada, que comprende no solo las competencias de un determinado organismo, sino que incluye las labores de otras personas jurídicas públicas, ha sido resaltado por la propia Corte Suprema. El máximo tribunal, a propósito del actuar de un órgano descentralizado, señaló que, si bien el accionar de los entes administrativos se basa en sus competencias propias, además debe considerar los elementos o antecedentes que obren en otros organismos públicos y que sean necesarios o atingentes con la materia que se deba decidir. La omisión de esta obligación genera una decisión carente de sustento (rol 58971-2016, 2017: considerando octavo y decimoprimero).

La importancia de esta resolución, para efectos de la exigencia de colaboración, radica en dos hechos. El primero es que el requerimiento de consulta que impone la Corte da vida a lo dispuesto en el artículo 37 bis de la Ley 19.880, que, para efectos de resguardar la colaboración entre organismos vinculados a una misma decisión, les impone el deber de consulta. El segundo, porque la omisión a este deber afecta la integridad que deben tener todos los actos del poder público, es decir, de este pronunciamiento judicial es posible desprender que el ejercicio de las propias competencias no puede ser excusa para aislarse de las atribuciones de otros organismos, cuya intervención, para efectos decisorios o de aplicación de alguna política pública, puede resultar fundamental. ${ }^{19}$

Este deber colaborativo, justificado en el artículo 1 de la Constitución Política y reconocido, al menos tácitamente, por el Máximo Tribunal, también ha sido resaltado por la Contraloría General de la República. El órgano de control, precisamente a propósito de los municipios y con respecto a una situación de emergencia, ha señalado que si bien la regla general es que las corporaciones municipales desarrollen sus funciones dentro de la comuna establecida como su ámbito espacial, ante situaciones de catástrofe que reclamen la colaboración de otros órganos de la Administración del Estado, y considerando el deber de otorgar protección a la población, estas corporaciones se encuentran facultadas para prestar su colaboración fuera del ámbito de su competencia territorial (Dictamen 3.000, 2017).

Es decir, la Contraloría, a través de una interpretación de carácter finalista (Encina Brevis, 2019: 14), refuerza el deber colaborativo entre organismos públicos por sobre un aspecto formal de distribución de competencias (territorio) con la finalidad de lograr el objetivo común de servicialidad impuesto a nivel constitucional.

Por tanto, el principio colaborativo impone a los municipios ejecutar acciones con-

19. Puede consultarse un análisis a este fallo, precisamente desde la perspectiva del deber de coordinación de los organismos públicos, en Cordero Vega (2020: 121-126). 
juntas y concertadas con una pluralidad de sujetos públicos (Cordero Vega, 2015: 204), a pesar de su autonomía y de la inexistencia de un vínculo relacional con el presidente de la República, con el objetivo de poner en movimiento el sistema del cual todos los entes administrativos forman parte, y lograr el fin general impuesto a la universalidad de los órganos estatales. Esta obligación es independiente de la necesidad específica que se deba satisfacer, es decir, sin importar si se encuentra ligada a las funciones propias de los municipios, de otros entes administrativos o de la máxima autoridad estatal.

Por lo mismo, si bien la declaración de un estado de excepción constitucional o la aplicación de la Ley 16.282 corresponden a una función gubernativa de la cual las corporaciones municipales se encuentran excluidas, esta exclusión se refiere al origen constitucional de la decisión no a su ejecución. En este último ámbito, los municipios deben colaborar como forma de lograr un sistema cohesionado y con propósito de servicio que permita cubrir un abanico diferente de prestaciones, y superar los diversos obstáculos y contrariedades que se presentan en la realidad (Boloña, 2010: 63).

\section{Deber de coordinación de los municipios con la función de gobierno}

La posibilidad que el ordenamiento jurídico le entrega a los entes administrativos de desarrollar sus competencias y colaborar con las atribuciones de otras personas jurídicas públicas debe complementarse con la exigencia de coordinación dispuesta en el artículo 5 de la Ley 18.575, a fin de lograr una acción conjunta y con ánimo de colaboración, sin que ello signifique una duplicidad o interferencias de funciones. El principio de coordinación consiste en un actuar público mancomunado, coherente, sin contradicciones entre sí, que busca facilitar la fluidez en la toma de decisiones y evitar trámites burocráticos, que podrían atentar en contra de una buena administración y debilitar la satisfacción oportuna y eficaz de las necesidades públicas (Boloña, 2010: 71 y 72).

Al respecto, la Corte Suprema ha señalado que la coordinación consiste en la disposición metódica y racional de las actividades que desarrollan los órganos administrativos, individualmente y en su conjunto, para el cumplimiento más eficiente y eficaz de la función administrativa y la mayor satisfacción de las necesidades colectivas a cargo del Estado. Su objetivo principal es procurar que las políticas, los planes, los programas y las acciones se cumplan y ejecuten oportunamente aunando una suma de esfuerzos a fin de alcanzar un efecto multiplicador en el grado de satisfacción de las necesidades colectivas por parte de los servicios administrativos (rol 37834-2017, 2017: considerando séptimo).

Es lógico que este deber también sea exigible a los municipios en virtud del principio de legalidad y por el hecho de ser integrantes de la Administración Pública. Es mas, a propósito de estas corporaciones y en el contexto de una emergencia, esta obligación resulta trascendental. ${ }^{20}$ En efecto, su relevancia se justifica, primero, por las caracterís-

20. Tan relevante es esta exigencia que la Corte Suprema, a propósito del terremoto de 2010, utilizó dentro de su argumentación, para efectos de determinar la responsabilidad de la Administración Pública 
ticas propias de dicho entorno, que son su dinamismo y complejidad con respecto al normal funcionamiento del Estado y de la sociedad, lo cual exige prontitud, eficiencia y eficacia para cubrir las necesidades de la zona afectada. Segundo, porque en lo referente a la prevención de riesgos y a la prestación de auxilio en situaciones de emergencia o catástrofe el municipio tiene atribuciones compartidas con otros órganos del Estado que resulta necesario coordinar (Fernández Richard, 2013: 155). Tercero, toda vez que, independiente de que nos encontremos en un contexto de excepción constitucional o de aplicación de la Ley 16.282, en ambos escenarios siempre intervendrán distintos organismos cuyas acciones será necesario integrar bajo este principio de unidad de acción.

Refuerza la importancia del deber de coordinación entre el municipio y otros servicios públicos, en el contexto de un terremoto, pandemia o agresión externa, la posibilidad de afectar derechos fundamentales. Como se sabe, estas medidas de afectación son adoptadas por autoridades que se encuentran en espacios territoriales distintos o alejados geográficamente del territorio comunal. Por tanto, resulta imprescindible una real y efectiva coordinación entre aquel que debe tomar la medida y quienes deben ejecutarla, a fin de generar una gestión pública oportuna y facilitar la idoneidad de la decisión, es decir, que esta sea ajustada o conforme a la realidad comunal.

Por tanto, las corporaciones edilicias tienen la obligación de coordinarse con otros organismos administrativos con el fin de lograr la máxima eficiencia en el cumplimiento de la función pública (Cea Egaña, 2012: 410). Este deber adquiere mayor significado en un contexto de excepción, en razón de la complejidad, el dinamismo y la adversidad de dicho escenario, por la posibilidad de afectar derechos fundamentales y por las funciones propias y compartidas de los municipios.

\section{Formas jurídicas municipales para concretar los deberes de colaboración y coordinación}

A nivel doctrinario, se señala como elemento diferenciador de ambas modalidades de actuación la relación vertical u horizontal existente entre los organismos públicos involucrados, es decir, que en la cooperación, las entidades cooperantes tienen la misma capacidad decisoria, a diferencia de lo que ocurre en la coordinación, que supone la existencia de un sujeto que coordina con un poder prevalente con respecto a los sujetos coordinados (Szmulewicz Ramírez, 2021: 190). No obstante esta diferencia, en nuestro ordenamiento jurídico es posible encontrar diferentes técnicas que le permiten a los

por falta de servicio, precisamente la falta de coordinación, al señalar: «en consecuencia, existen elementos de juicio suficientes para establecer que los organismos del Estado desplegaron un servicio de prevención deficiente y no ajustado a los protocolos vigentes respecto de un hecho posible en una zona vulnerable, resultando evidente que no se desarrollaron con eficacia las labores de prevención y coordinación que el ordenamiento jurídico le había encomendado ante situaciones de catástrofes, todo lo cual permite afirmar que se incurrió en falta de servicio» (rol 4658-2017, 2017: considerando decimosexto de la sentencia de reemplazo). Lo mismo en causa rol 18225- 2017, 2018: considerando cero de la sentencia de reemplazo. 
municipios dar vida a ambos deberes en su relación con el poder central, sin que ello signifique alterar su autonomía, y que pueden concretarse en diferentes contextos, por ejemplo, aquellos producidos producto de una situación de emergencia.

Primero, a propósito de la coordinación, valga señalar que la propia Carta Fundamental, en su artículo 123, mandata al legislador a establecer fórmulas de unidad de acción entre los municipios, y entre estos y los demás servicios públicos. Por consiguiente, es la norma fundamental la que engarza las relaciones interadministrativas precisamente en tal principio (Szmulewicz Ramírez, 2021: 188). Dentro de estas fórmulas legales se encuentra lo dispuesto en el artículo 63, letras k y l de la Ley Orgánica Constitucional de Municipalidades, que le entregan al alcalde el deber de coordinar: i) el funcionamiento municipal con los órganos de la Administración del Estado que correspondan; y ii) la acción de los servicios públicos en el territorio de la comuna, en concordancia con lo dispuesto en el inciso 8 del artículo 118 del texto político, que le impone a los servicios públicos que desarrollan su labor en el territorio comunal el deber de coordinarse con el respectivo municipio, es decir, armonizar con el ente edilicio aquellas funciones propias de organismos administrativos y que no son municipales.

Como se desprende de las normas previas, es el alcalde, como máxima autoridad municipal, el primer responsable en concretar modalidades de actuación que permitan coordinar la labor municipal con las funciones propias del poder central. En consecuencia, es dicha autoridad comunal quien debe propender al logro de acuerdos entre el municipio y los servicios públicos que funcionan en la comuna, como técnica expresa y concreta de coordinación contenida en el artículo 10 de la misma ley orgánica; o bien, y de conformidad a la misma norma, es también el alcalde quien debe requerir la intervención del delegado presidencial provincial a falta de acuerdo.

En este último supuesto, creemos que mas que una acción de coordinación por parte del representante del ejecutivo se estaría en presencia de una mediación, toda vez que el delegado presidencial ejercería una actividad de asesoramiento o ayuda (Bermúdez, 2014: 125) que facilite la coordinación interadministrativa mas que una función decisoria dado el caso de que carece de un poder prevalente con respecto al alcalde y porque la misma norma señala que, en ningún caso, se podrán alterar las atribuciones y funciones que correspondan a los organismos respectivos, es decir, que en ningún caso se podrá sobrepasar la autonomía municipal.

Estos acuerdos, como expresión de coordinación, se entiende que sean adoptados, en un primer momento, de manera informal, por ejemplo a través de reuniones, conversaciones y negociaciones que propendan a la unidad acción (Bermúdez, 2014: 388 y 389 ), con mayor razón si se adquieren en un contexto de anormalidad institucional, por la urgencia que este escenario impone. Sin embargo, en una segunda etapa, y por necesidades de certeza y seguridad jurídica, se hace necesario una formalidad, por ejemplo, a través de la celebración de convenios de conformidad al artículo 8 de la misma ley orgánica. Norma que, al igual que lo ocurre con el artículo 10, protege la autonomía municipal en sus relaciones de colaboración y/o coordinación con el poder central, toda vez que prohíbe alterar las atribuciones y funciones que corresponden a los municipios. 
Otra forma a través de la cual se pueden concretar estas modalidades se encuentra en el artículo 9 de la ley orgánica indicada, que impone a las corporaciones edilicias actuar dentro del marco de los planes nacionales y regionales que regulen una determinada actividad. Esta disposición se encuentra relacionada, entre otras materias, con situaciones de emergencia, toda vez que la Ley 21.364, que establece el sistema nacional de prevención y respuesta ante desastres, señala que los planes nacionales, regionales y comunales para la gestión del riesgo por desastres deberán estar en consonancia, armonía y sistematicidad entre sí, primando los de alcance nacional y regional por sobre lo comunal. En consecuencia, el orden jurídico exige a los municipios armonizar sus planes comunales de emergencia con lo contenido en los de alcance nacional y regional, primando estos últimos, lo cual se entiende en razón del carácter unitario del Estado, que impone a organismos administrativos territoriales, por ejemplo, los municipios, a someterse estrictamente a las normas legales y reglamentarias de alcance general (Cordero Vega, 2015: 124).

Por último, cabe reiterar lo dicho a propósito del artículo 37 bis de la Ley 19.880, que impone la obligación de consulta con el objeto de resguardar la colaboración entre entes públicos involucrados en una misma decisión.

\section{Conclusiones}

Este trabajo tuvo como finalidad otorgar una explicación que permitiera aclarar los ámbitos de competencia entre autoridades centrales y comunales en un contexto de excepción constitucional. En razón de ello, se pudo observar, primero, que la estructura unitaria que rige al país concentra la función de gobierno en una sola autoridad, cual es el presidente de la República y, segundo, que las características que le otorgan fisonomía a dicha labor, discrecionalidad y relevancia estatal proceden tratándose de la declaración de un estado de excepción. Por tanto, al reunir los elementos propios de un acto de gobierno, dicho pronunciamiento es de competencia exclusiva del jefe de Estado. También lo son las medidas que se pueden adoptar en tal escenario, especialmente aquellas relacionadas con derechos fundamentales.

Si bien lo anterior significa excluir la titularidad de cualquier otro organismo producto del principio de juridicidad, no se puede ignorar el carácter autónomo que la propia Carta Fundamental le entrega a las municipalidades, como herramienta para concretar sus funciones propias y compartidas. Sin embargo, se pudo observar que esta libertad no hace competente a los municipios para adoptar decisiones de gobierno, ni siquiera bajo una situación de emergencia o catástrofe. Primero, por lo señalado a propósito del centralismo en la función de gobierno y, segundo, porque el presidente de la República no puede prolongar sus tareas políticas en el territorio comunal, toda vez que sus autoridades son elegidas democráticamente por la ciudadanía no designadas por el jefe de Estado.

Por último, se concluyó que, a pesar de esta exclusión de la función de gobierno, las corporaciones municipales sí pueden intervenir en un escenario de excepción como 
consecuencia de formar parte de un único sistema administrativo que impone un deber de actuación colaborativo y cooperativo como presupuestos necesarios para cumplir la finalidad de servicio que se le impone a todo el Estado, independiente de las competencias propias y del origen de la necesidad.

Como conclusión general, se pudo apreciar la importancia de transparentar las competencias de autoridades centrales y comunales, toda vez que ello permite potenciar el Estado de derecho y proteger garantías fundamentales, principalmente en un escenario incierto y que genera vulnerabilidad en las personas.

\section{Referencias}

BASSA, Jaime (2020). «Emergencia y estados de excepción constitucional». En Pablo Contreras (editor), La ley de la emergencia: Ensayos sobre el derecho, la excepción y la pandemia. Santiago: Der.

Bermúdez Soto, Jorge (2014). Derecho administrativo general. 3. ${ }^{a}$ ed. Santiago: Thomson Reuters.

Boloña Kelly, Germán (2010). Organización administrativa. Santiago: Legal Publishing.

Caldera Delgado, Hugo (1989). «Límites constitucionales de la discrecionalidad administrativa». Revista Chilena de Derecho, 16 (2): 424-428. Disponible en https://bit. ly/3sQoOKP.

-. (1991). «Función de gobierno y función administrativa». Revista de Derecho Público, 49: 205-215. Disponible en https://bit.ly/3Dkfp63.

CAMACho CéPeda, Gladys (2010). Tratado de derecho administrativo: La actividad sustancial de la Administración del Estado. Santiago: Legal Publishing.

CEA Egaña, José Luis (1991). «Fiscalización política o control judicial del acto de gobierno». Gaceta Jurídica, 137: 9-34.

-. (1997). "Qué es gobierno: Una respuesta constitucional». Revista de Derecho Universidad Austral de Chile, 8: 61-76. Disponible en https://bit.ly/3zjNSPM.

-. (2012). Renovación del constitucionalismo en Chile. Santiago: Legal Publishing.

Celis Danzinger, Gabriel (2010). Curso de derecho administrativo. Santiago: Thomson Reuters.

Chible Villadangos, Pía (2020). «El poder ejecutivo como Administración del Estado». Revista de Derecho Público, 92: 37-7o. Disponible en https://bit.ly/3mLwpN1.

Cordero Vega, Luis (2015). Lecciones de derecho administrativo. Santiago: Legal Publishing.

-. (2020). El derecho administrativo chileno: Crónicas desde la jurisprudencia. Santiago: Ediciones Der.

ENCINA BREvis, Juan (2019). «La competencia extraterritorial de las municipalidades: El caso CARES». Revista de Derecho Público, 90: 41-6o. Disponible en: https://bit. ly/3jh5ygf.

FAYT, Carlos (1998). Derecho político. Tomo II. Buenos Aires: Depalma. 
FERnÁndez Richard, José (2013). «Las administraciones del Estado y las Municipalidades en Chile». Revista del Instituto de Ciencias Jurídicas de Puebla, 7: 148-16o. Disponible en https://bit.ly/3myjON2.

García DE Enterría, Eduardo y Tomás-Ramón Fernández (2017). Curso de derecho administrativo. Tomo I. Navarra: Thomson Reuters.

Huidobro, Ramón (2011). Tratado de derecho administrativo: Derecho y administración comunal. Tomo III. Santiago: Legal Publishing.

Jiménez Larraín, Fernando y Fernando Jiménez Loosli (2013). Derecho político. 2. ${ }^{\mathrm{a}}$ ed. Concepción: Universidad Católica de la Santísima Concepción.

Martínez Sospedra, Manuel y Ainhoa Uribe Otalora (2018). Teoría del Estado y de las formas políticas: Sistemas políticos comparados. Madrid: Tecnos.

Pantoja Bauzá, Rolando (200o). «El principio de la juridicidad». Revista de Derecho Público, 62: 156-168. Disponible en https://bit.ly/3pXhpNE.

-. (2010). Tratado de derecho administrativo: Derecho y Administración del Estado. Tomo I. Santiago: Legal Publishing.

Pfeffer Urquiaga, Emilio (2002). «Estados de excepción constitucional y reforma constitucional». Ius et Praxis, 1: 223-250. Disponible en https://bit.ly/3CCcSDJ.

Silva Irarrázaval, Luis (2018). «El control judicial de los estados de excepción constitucional: La supremacía del presidente de la República». Revista Chilena de Derecho, 45 (1): 81-103. Disponible en https://bit.ly/38arHzR.

Soto Delgado, Pablo (2021). «La resurrección de la policía sanitaria municipal durante la pandemia de covid-19: Una cuestión de densidad legal en clave históricanormativa». En Christian Rojas, Juan Carlos Ferrada Bórquez y Pablo Méndez Ortiz (coordinadores), Derecho Público y Emergencia. Santiago: Thomson Reuters.

Soто KLoss, Eduardo (2010). Derecho administrativo: Temas Fundamentales. Santiago: Legal Publishing.

Szmulewicz Ramírez, Esteban (2021). «Problemas de coordinación entre niveles de gobierno: Perspectivas a partir de los impactos del covid-19». En Christian Rojas, Juan Carlos Ferrada Bórquez y Pablo Méndez Ortiz (coordinadores), Derecho Público y Emergencia. Santiago: Thomson Reuters.

Tejos Canales, Álvaro (2006). «Estados de excepción constitucional». Revista de Derecho Público, 68: 138-148. Disponible en https://bit.ly/3EyoK7d.

VAldivia, José Miguel (2020). «Emergencia y Administración». En Pablo Contreras (editor), La ley de la emergencia: Ensayos sobre el derecho, la excepción y la pandemia. Santiago: Der.

ZÚÑIGA UrbINA, Francisco (2007). «Autonomías constitucionales e instituciones contramayoritarias (a propósito de las aporías de la "Democracia Constitucional”». Ius et Praxis, 13 (2): 223-244. Disponible en https://bit.ly/2Y6csGH.

-. (2014). «El derecho de excepción y la responsabilidad del Estado: Falta de servicio y acto de gobierno. Comentario de la sentencia de casación rol 4029-2013 de la Corte Suprema, de 24 de diciembre de 2013». Estudios Constitucionales, 12 (1): 503-526. Disponible en https://bit.ly/3Bb76HR. 


\section{Sobre la autora}

Valeska Opazo de la Fuente es abogada, licenciada en Derecho por la Universidad Católica de la Santísima Concepción de Chile y doctora en Derecho por la Pontificia Universidad Católica de Chile. Actualmente, es profesora de Derecho Administrativo en la Facultad de Derecho de la Universidad Católica de la Santísima Concepción de Chile. Su correo electrónico es vaopazo@ucsc.cl. (D) https://orcid.org/0000-0003-4178-9653. 
